\title{
Bisindoylmaleimide I enhances osteogenic differentiation
}

\author{
Fangfang Zhou ${ }^{1,2}$, Huizhe Huang ${ }^{2}$, Long Zhang ${ }^{1 凶}$ \\ ${ }^{1}$ Department of Molecular Cell Biology and Centre for Biomedical Genetics, Leiden University Medical Center, Leiden, \\ The Netherlands \\ 2 Faculty of Basic Medical Sciences, Chongqing Medical University Medical College, Chongqing 071007, China \\ $\square$ Correspondence: L.Zhang@lumc.nl (L. Zhang), devbiology@cqmu.edu.cn (H. Huang) \\ Received January 3, 2012 Accepted February 8, 2012
}

\begin{abstract}
The Wnt/ $\beta$-catenin and bone morphogenetic proteins (BMPs) pathways play important roles in controlling osteogenesis. Using a cell-based kinase inhibitor screening assay, we identified the compound bisindoylmaleimide I (BIM) as a potent agonist of the cytosolic $\beta$-catenin accumulation in preosteoblast cells. Through suppressing glycogen synthase kinase $3 \beta$ enzyme activities, BIM upregulated $\beta$-catenin responsive transcription and extended duration of BMP initiated signal. Functional analysis revealed that BIM promoted osteoblast differentiation and bone formation. The treatment of human mesenchymal stem cells with BIM promoted osteoblastogenesis. Our findings provide a new strategy to regulate mesenchymal stem cell differentiation by integration of the cellular signaling pathways.
\end{abstract}

KEYWORDS bisindoylmaleimide I, Wnt/ $\beta$-catenin, glycogen synthase kinase $3 \beta$, bone morphogenetic protein, human mesenchymal stem cells (hMSCs), osteogenesis

\section{INTRODUCTION}

Bone differentiation is controlled by signaling networking including the bone morphogenetic proteins (BMPs)/transforming growth factor (TGF- $\beta$ ) and Wnt pathways. Bone morphogenetic proteins (BMPs), members of the TGF- $\beta$ superfamily, activate its receptors and initiate phosphorylation of the downstream effector proteins, known as receptor-regulated Smads, leading to signal transduction. BMPs play pivotal roles and are involved in nearly all processes associated with skeletal morphogenesis (ten Dijke, 2006).

$\mathrm{Wnt} / \beta$-catenin signaling is another key signaling pathway required for bone formation and bone homeostasis. In the presence of Wnt ligand, frizzled (Fz) and low-density lipoprotein receptor-related protein-5 or 6 (LRP-5/6) co-receptors recruit Disheveled (Dvl) to the plasma membrane along with Axin-GSK3 $\beta$, inhibiting the formation of $\beta$-catenin destruction complex, allowing $\beta$-catenin levels to increase and the activation of $\mathrm{Wnt} / \beta$-catenin pathway (Behrens et al., 1996; Brunner et al., 1997; Zhang and Ma., 2010). Wnt/ $\beta$-catenin pathway directly targets Runx2 expression and promotes mineralization during osteoblastogenesis (Gaur et al., 2005). The canonical Wnt blocks apoptosis and osteoclastogenesis by increasing the OPG/RANKL ratio (Glass et al., 2005; Holmen et al., 2005; Spencer et al., 2006). Mutations in LRP-5 profoundly affect skeletal development and result in low bone mass (Gong et al., 2001; Little et al., 2002). The Dickkopf-1 (Dkk-1) resistant LRP5V171 mutation leads to high bone density (Boyden et al., 2002). Conditional deletion of the $\beta$-catenin gene in osteoblasts leads to reduced bone mass, and osteocyte-specific $\beta$-catenin-deficient mice develop low bone mass phenotype (Glass et al., 2005; Kramer et al., 2010). Increasing evidences also indicate that autocrine Wnt signaling is required for BMP in inducing bone formation (Rawadi et al., 2003; Fujita and Janz, 2007; Qiang et al., 2008; Tang et al., 2009; Honda, et al., 2010).

As a critical kinase involved in controlling both $\mathrm{Wnt} / \beta$ catenin and BMP signaling, glycogen synthase kinase $3 \beta$ (GSK3 $\beta$ ) serves as an effective therapeutic target for bone disease treatment. In this study, we show that through suppressing GSK3 $\beta$ kinase activity, bisindoylmaleimide I (BIM) promotes $W n t / \beta$-catenin signaling and prolongs duration of BMP induced Smad pathway in preosteoblast cells. Functional read out measured it as a bone-specific alkaline phosphatase 
(ALP) activator and mineralization assay uncovered it as a potent osteogenic inducer, which is further proved to regulate osteoblast differentiation from mesenchymal stem cells.

\section{RESULTS}

\section{BIM stimulates cytosolic $\beta$-catenin accumulation in preosteoblast cells}

Forming of osteoblasts contributes to bone resorption and treatment of bone diseases. We started this project with a screen to identify kinase inhibitors that could elevate cytosolic $\beta$-catenin level in preosteoblast cells. KS483 cells were treated with suboptimal doses of kinase inhibitors and then assayed for cytosolic $\beta$-catenin expression. Among all the 40 compounds tested, BIM appeared to be the most potent in triggering cytosolic $\beta$-catenin accumulation (Fig. 1). We then focused our attention on its applications in osteogenic differentiation.

\section{BIM enhances osteogenic differentiation}

It is well established that cytosolic $\beta$-catenin accumulation is a key factor that determines Wnt induced osteoblast differentiation and bone formation. We then investigated $\mathrm{C} 2 \mathrm{C} 12$ myoblast and KS483 preosteoblast cells that were treated with BIM. As shown in Fig. 2, BIM treatment dose-dependently increased ALP activity in C2C12 cells (Fig. 2A). Quantitative real-time RT-PCR analysis indicated that osteogenic marker genes, such as OPG and Runx2, were elevated upon

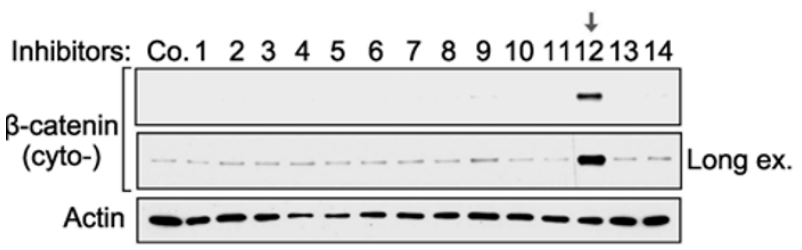

Inhibitors: Co.151617181920212223242526

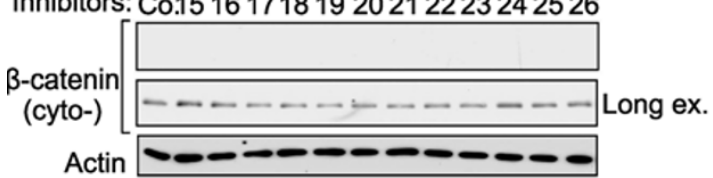

Inhibitors: Co.2728293031323334353637383940

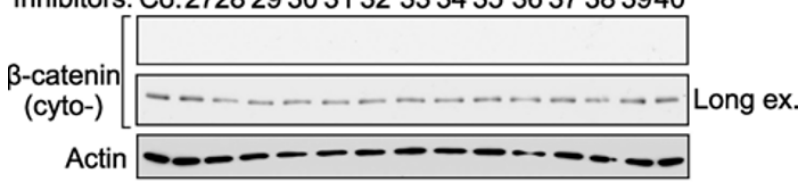

Figure 1. Identification of bisindoylmaleimide I (BIM) as a potent compound triggering cytosolic $\beta$-catenin accumulation in preosteoblast cells. KS483 cells were treated with 40 kinds of kinase inhibitors (listed in Table 1) for $1 \mathrm{~h}$, cells were harvested, the membrane and cytosolic fractions were isolated, and cytosolic $\beta$-catenin and Actin were detected by western blotting. The arrow indicates BIM treatment (No.12).
Table 140 kinds of kinase inhibitors

\begin{tabular}{|c|c|c|c|}
\hline & Inhibitors & $\begin{array}{l}\text { Final con- } \\
\text { centration } \\
(\mu \mathrm{mol} / \mathrm{L})\end{array}$ & $\begin{array}{l}\text { Potential target } \\
\text { (pathway) }\end{array}$ \\
\hline Control & DMSO & & - \\
\hline 1 & SB-203580:p38 & 10 & p38 MAPK \\
\hline 2 & $\begin{array}{l}\mathrm{H}-7: P K A, P K G, M L C K \\
\text { and PKC }\end{array}$ & 10 & $\begin{array}{l}\text { PKA, PKG, } \\
\text { MLCK and PKC }\end{array}$ \\
\hline 3 & $\begin{array}{l}\mathrm{H}-9: P K A, P K G, M L C K \\
\text { and PKC }\end{array}$ & 10 & $\begin{array}{l}\text { PKA, PKG, } \\
\text { MLCK and PKC }\end{array}$ \\
\hline 4 & AG-494 & 10 & $\begin{array}{l}\text { EGFRK, } \\
\text { PDGFRK }\end{array}$ \\
\hline 5 & AG-825 & 10 & EGFRK \\
\hline 6 & Lavendustin A & 10 & EGFRK \\
\hline 7 & RG-14620 & 10 & EGFRK \\
\hline 8 & Tyrphostin 23 & 10 & EGFRK \\
\hline 9 & AG-879 & 10 & NGFRK \\
\hline 10 & AG-370 & 10 & PDGFRK \\
\hline 11 & Tyrphostin 9 & 10 & PDGFRK \\
\hline 12 & Bisindoylmaleimide I & 10 & PKC \\
\hline 13 & $\mathrm{H}-8$ & 10 & PKA, PKG \\
\hline 14 & HA-1004 & 10 & PKA, PKG \\
\hline 15 & HDBA & 10 & EGFRK, CaMK II \\
\hline 16 & $\mathrm{KN}-62$ & 10 & CamK II \\
\hline 17 & ML-7 & 10 & MLCK \\
\hline 18 & N9-isopropyl-olomourcine & 10 & CDK \\
\hline 19 & LFM-A13 & 10 & BTK \\
\hline 20 & SB-202190 & 10 & p38 MAPK \\
\hline 21 & PP2 & 10 & Src-family \\
\hline 22 & ZM 336372 & 10 & cRAF \\
\hline 23 & SU 4312 & 10 & Flk-1 \\
\hline 24 & AG-1296 & 10 & PDGFRK \\
\hline 25 & GW 5074 & 10 & cRAF \\
\hline 26 & ZM 449829 & 10 & JAK-3 \\
\hline 27 & DRB & 10 & CK II \\
\hline 28 & SP600125 & 10 & JNK \\
\hline 29 & Y-27632 & 10 & ROCK \\
\hline 30 & BML-257 & 10 & Akt \\
\hline 31 & SC-514 & 10 & IKK-2 \\
\hline 32 & BML-259 & 10 & Cdk5/p25 \\
\hline 33 & HNMPA & 10 & IRK \\
\hline 34 & Damnacanthal & 10 & p56 lck \\
\hline 35 & Piceatannol & 10 & Syk \\
\hline 36 & PP1 & 10 & Src-family \\
\hline 37 & AG-490 & 10 & JAK-2 \\
\hline 38 & AG-126 & 10 & IRAK \\
\hline 39 & AG-370 & 10 & PDGFRK \\
\hline 40 & AG-879 & 10 & NGFRK \\
\hline
\end{tabular}


A

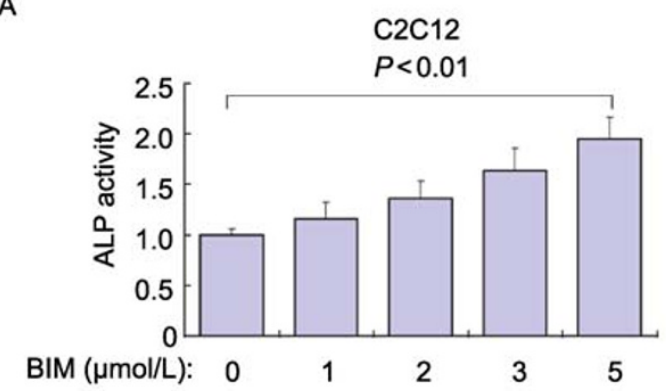

B

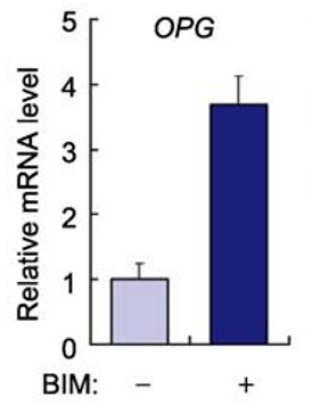

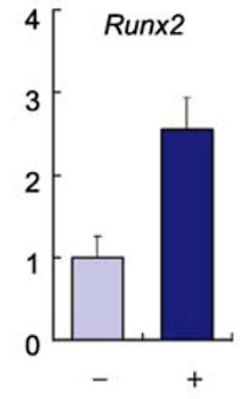

C

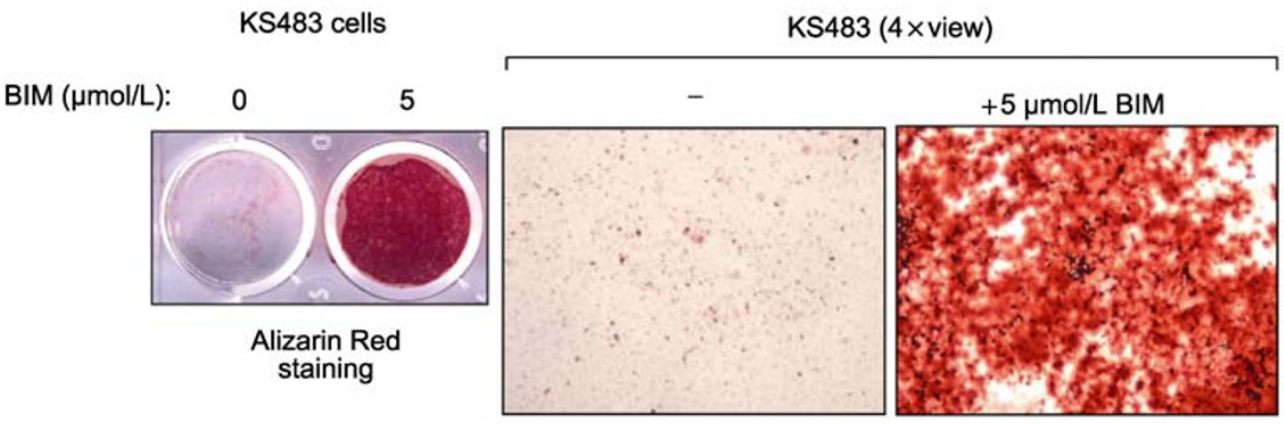

Figure 2. Bisindoylmaleimide I (BIM) enhances osteogenic differentiation. (A) $\mathrm{C} 2 \mathrm{C} 12$ cells were treated with increasing doses of BIM for 4 days. Cells were then harvested for histochemical examination of alkaline phosphatase (ALP) activity. The histochemically stained cell material was dissolved in $50 \mathrm{mmol} / \mathrm{L} \mathrm{NaOH}$ in ethanol, and absorbance was measured at $550 \mathrm{~nm}$. Data show the mean and SD of triplicates. (B) Q-PCR analysis of BIM ( $5 \mu \mathrm{mol} / \mathrm{L})$ treated $\mathrm{C} 2 \mathrm{C} 12$ cells. The relative mRNA levels shown were normalized to the levels of GAPDH as internal control. For each gene the mRNA level in this control is set at "1." Values and error bars represent the mean \pm SD of triplicates. (C) KS483 cells were treated with or without BIM (as indicated) in medium containing Vitamin $C(50 \mu \mathrm{g} / \mathrm{mL})$ and $\beta$-glycerolphosphate $(5 \mu \mathrm{mol} / \mathrm{L})$ for 4 days; 4 days later, the medium was replaced by normal medium containing $10 \% \mathrm{FBS}$, Vitamin $\mathrm{C}(50 \mu \mathrm{g} / \mathrm{mL})$ and $\beta$-glycerolphosphate $(5 \mu \mathrm{mol} / \mathrm{L})$ for another 4 days. Cells were then fixed and stained with Alizarin Red for analysis of mineralization.

BIM treatment (Fig. 2B). And in KS483 cells, BIM significantly induced mineralization (Fig. 2C). Taken these data together, BIM may act as a potent osteogenic inducer through $\mathrm{Wnt} / \beta$ catenin signaling pathway.

\section{BIM activates Wnt/ $\beta$-catenin signaling by suppressing GSK3 $\beta$ in preosteoblast cells}

We next examined the underlying mechanism of BIM on canonical Wnt signaling. Reporter assay showed that the activity of Wnt-responsive TopFlash-Luc (Korinek et al., 1997) and LEF-Luc (Hsu et al., 1998) were dose-dependently increased by BIM in $\mathrm{C} 2 \mathrm{C} 12$ and KS483 cells whereas BMPresponsive BRE-Luc (Korchynskyi and ten Dijke, 2002) was not affected (Fig. 3A-3D). The activation of Topflash-luciferase by BIM was Wnt-specific, since the control reporter Fopflash-luciferase was not stimulated (data not shown). Furthermore, Wnt3a-induced TopFlash luciferase activity could be inhibited by DKK1, active GSK3 $\beta$ and dominant negative LEF-1 (dnLEF-1), whereas BIM-induced reporter activity could only be inhibited by active GSK3 $\beta$ and dnLEF-1, but not by
DKK1. This indicates that BIM may not play a role by stimulating Wnt secretion but act on the downstream signaling cascades (Fig. 3E and $3 \mathrm{~F}$ ). To prove this hypothesis, we treated KS483 cells with BIM and performed immunoblot analysis. Consistent with previous findings, $\beta$-catenin was accumulated in BIM treated cells. Notably, western blot analysis with phospho-specific anti- $\beta$-catenin antibodies showed that Wnt3a-CM and SB216763 inhibited the phosphorylation of $\beta$-catenin at the Ser33/37/Thr41 residues (Fig. 3G). Treatment with BIM also inhibited Ser33/37/Thr41 phosphorylation without affecting the phosphorylation of $\beta$-catenin at Ser552 and Ser675 (Fig. 3G), two previously identified phosphorylation sites by Akt and PKA respectively (Hino et al., 2005; Taurin et al., 2006; Fang et al., 2007; He et al., 2007). Additionally, phosphorylation of GSK3 $\beta$ at Ser9 was observed to be downregulated by BIM. These data indicate that BIM inhibits GSK3 $\beta$ kinase activity, and thus allows canonical Wnt activation.

\section{BIM induces osteogenesis via Wnt/ $\beta$-catenin pathway}

We showed that BIM activates Wnt/B-catenin signaling and 
A

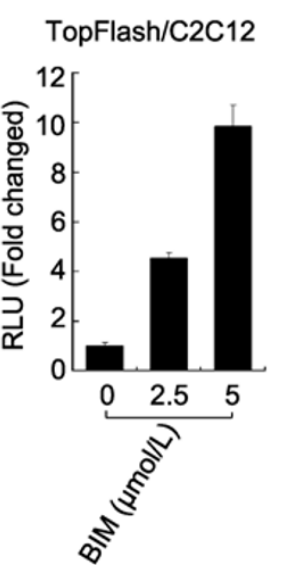

B

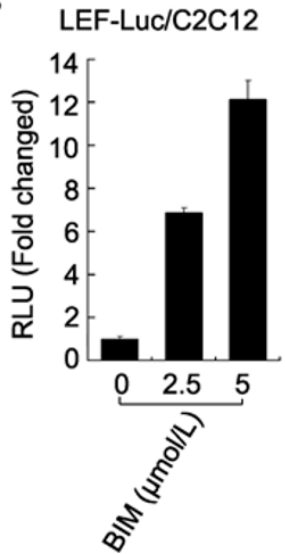

E

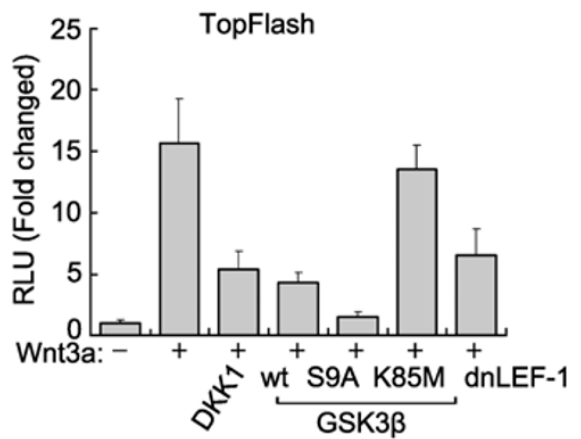

$\mathrm{F}$

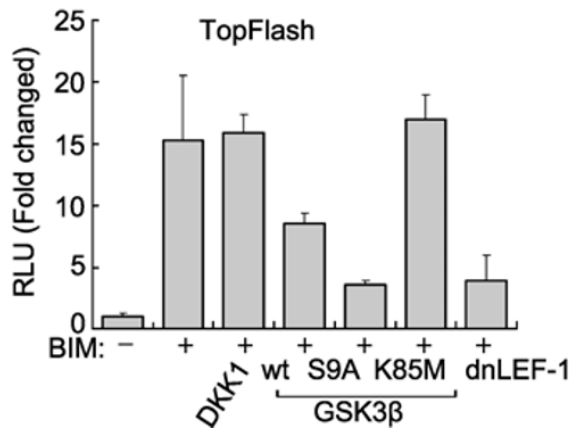

C

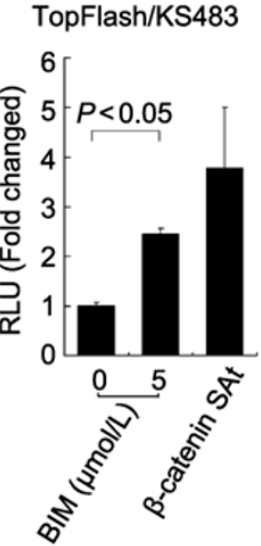

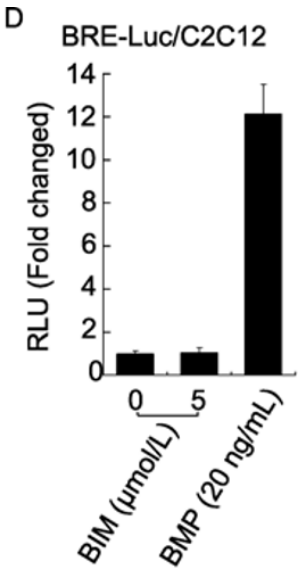

G

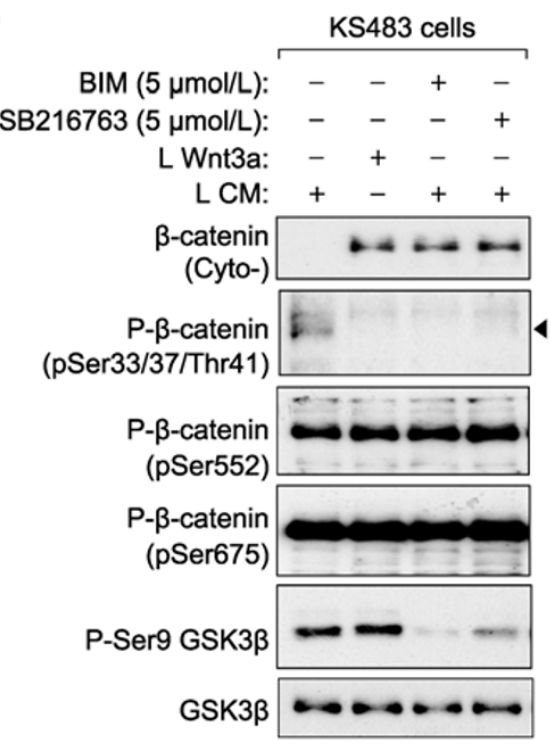

Figure 3. Bisindoylmaleimide I (BIM) activates Wnt signaling. (A and B) C2C12 cells were transfected with TopFlash-Luc (A) or LEF-Luc (B) and treated with different doses of BIM as indicated for $8 \mathrm{~h}$. Cells were harvested and luciferase activity was measured. (C) BIM induced TopFlash-Luc activity in KS483 cells. Constitutively active $\beta$-catenin SA mutant served as control. (D) BIM had no effect on basal level BRE-Luc reporter activity. BMP6 treatment for $8 \mathrm{~h}$ as control; For A-D, data are the mean \pm SD. RLU, relative luciferase units. (E and F) HEK293T cells were transfected with TopFlash-Luc along with DKK1, GSK3 $\beta$ wt, GSK3 $\beta$ S9A, GSK3 $\beta$ K85M and dnLEF-1 as indicated. Cells were then treated with Wnt3a (E) or BIM (F) for overnight and harvested for luciferase activity analysis. (G) Immunoblot analysis of KS483 cells treated with BIM, SB216763 or L control/L Wnt3a conditioned medium. L CM, L cells control conditioned medium; L Wnt3a, L cells secreted Wnt3a conditioned medium.

promotes osteogenic differentiation. To further test whether $\beta$-catenin mediated signaling is required for BIM-induced osteogenesis, siRNAs that specifically silence $\beta$-catenin were used to serve this purpose. Firstly, BIM as well as Wnt3a stimulated Wnt reporter activity was abolished by si- $\beta$-catenin (Fig. 4A). Secondly in KS483 cells, measurement of ALP activity and Alizarin red staining analysis showed that efficient depletion of endogenous $\beta$-catenin in KS483 cells partially blocked BIM-induced ALP activity and mineralization (Fig. 4B and $4 \mathrm{C}$ ). These data indicate that BIM induces bone forma- tion by activating $\mathrm{Wnt} / \beta$-catenin pathway.

\section{BIM enhances duration of BMP-induced signaling}

Although basal BMP reporter was not stimulated by BIM (Fig. 3D), we observed elevated BMP responses when BIM was co-treated with BMP ligand in cells (Fig. 5A). This suggests that BIM facilitates BMP ligand-induced signaling. As Smad1 phosphorylation in linker region by GSK3 $\beta$ induces its instability (Fuentealba et al., 2007), we investigated whether BIM 
A

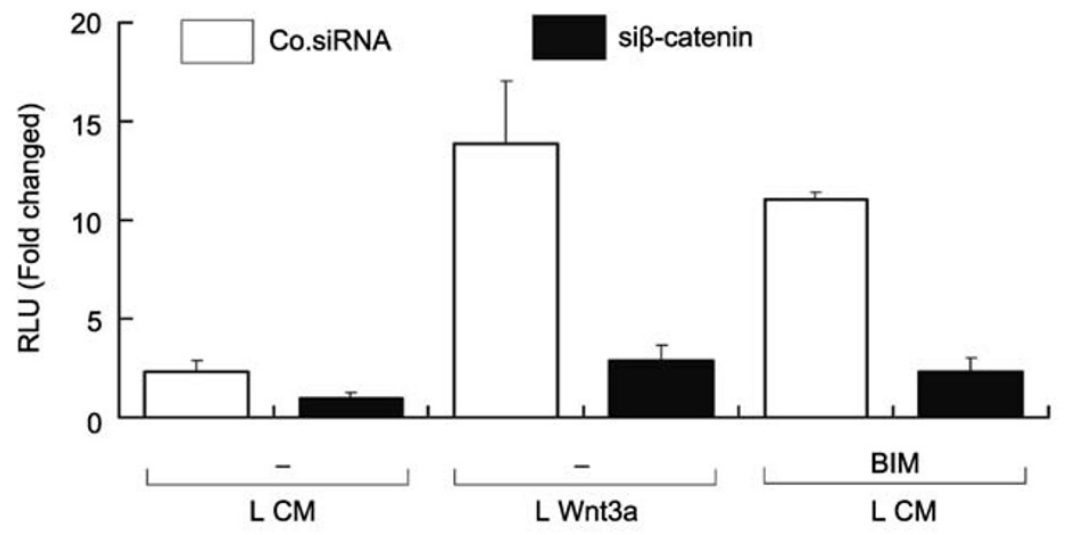

B
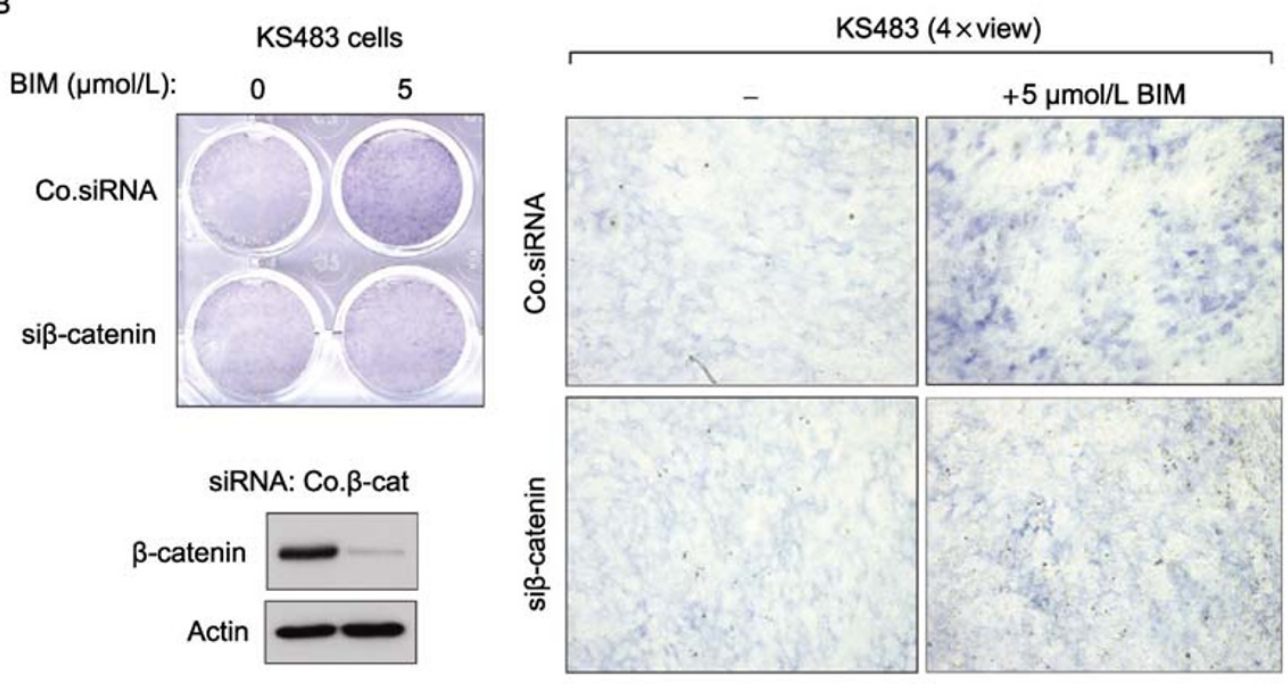

C
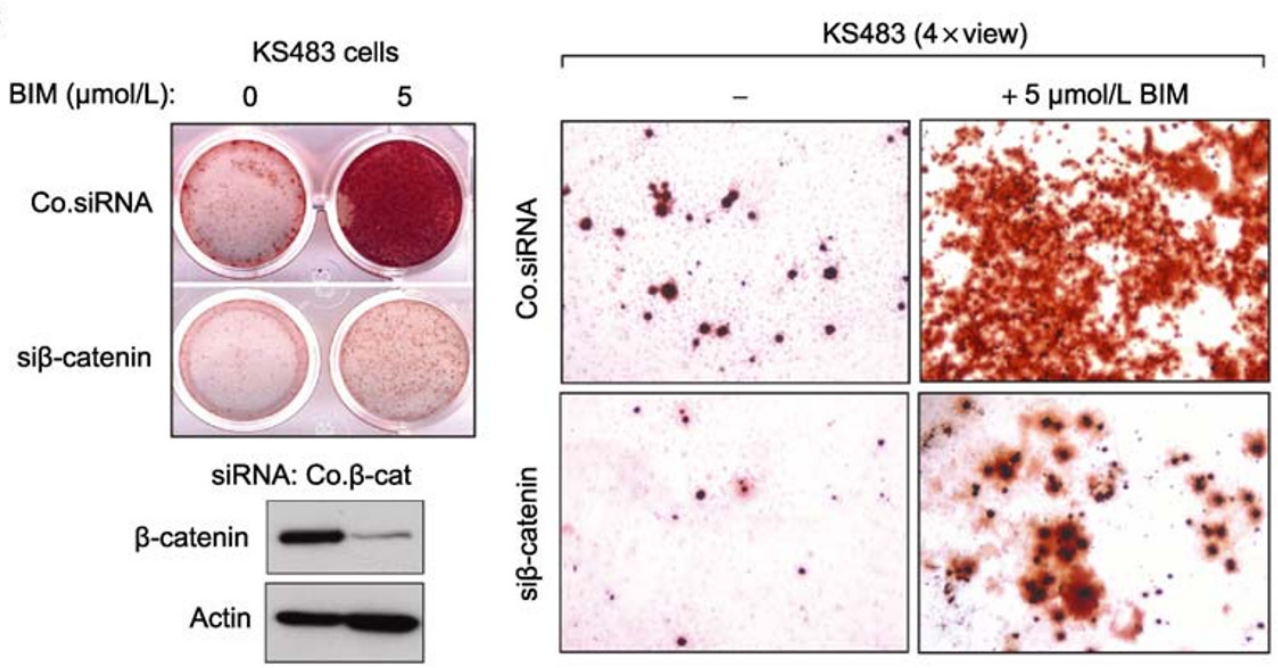

Figure 4. Bisindoylmaleimide I (BIM) promotes osteogenesis via $\beta$-catenin mediated signaling. (A) $\beta$-catenin depletion by siRNA abolished BIM-induced TopFlash-Luc activity. RLU, relative luciferase unit; $L C M, L$ cells control conditioned medium; $L$ Wnt3a, L cells secreted Wnt3a conditioned medium. (B) Left upper panel: $\beta$-catenin depletion inhibits BIM-induced ALP activity in KS483 cells. Left lower panel: Immunoblotting analysis showing $\beta$-catenin knockdown efficiency. Right panel: $4 \times$ view of left upper panel. (C) Left upper panel: $\beta$-catenin depletion inhibits BIM-induced mineralization in KS483 cells. Left lower panel: Immunoblotting analysis showing $\beta$-catenin knockdown efficiency. Right panel: $4 \times$ view of left upper panel. For A-C, Co.siRNA, control siRNA; si $\beta$-catenin, $\beta$-catenin siRNA. 
A

BRE-Luc/KS483

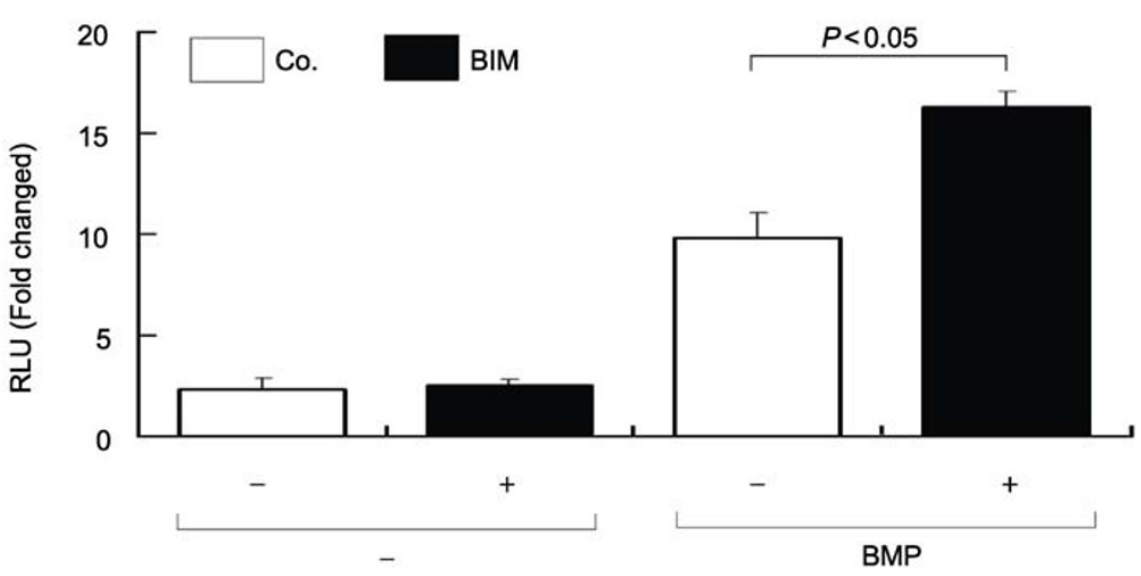

B

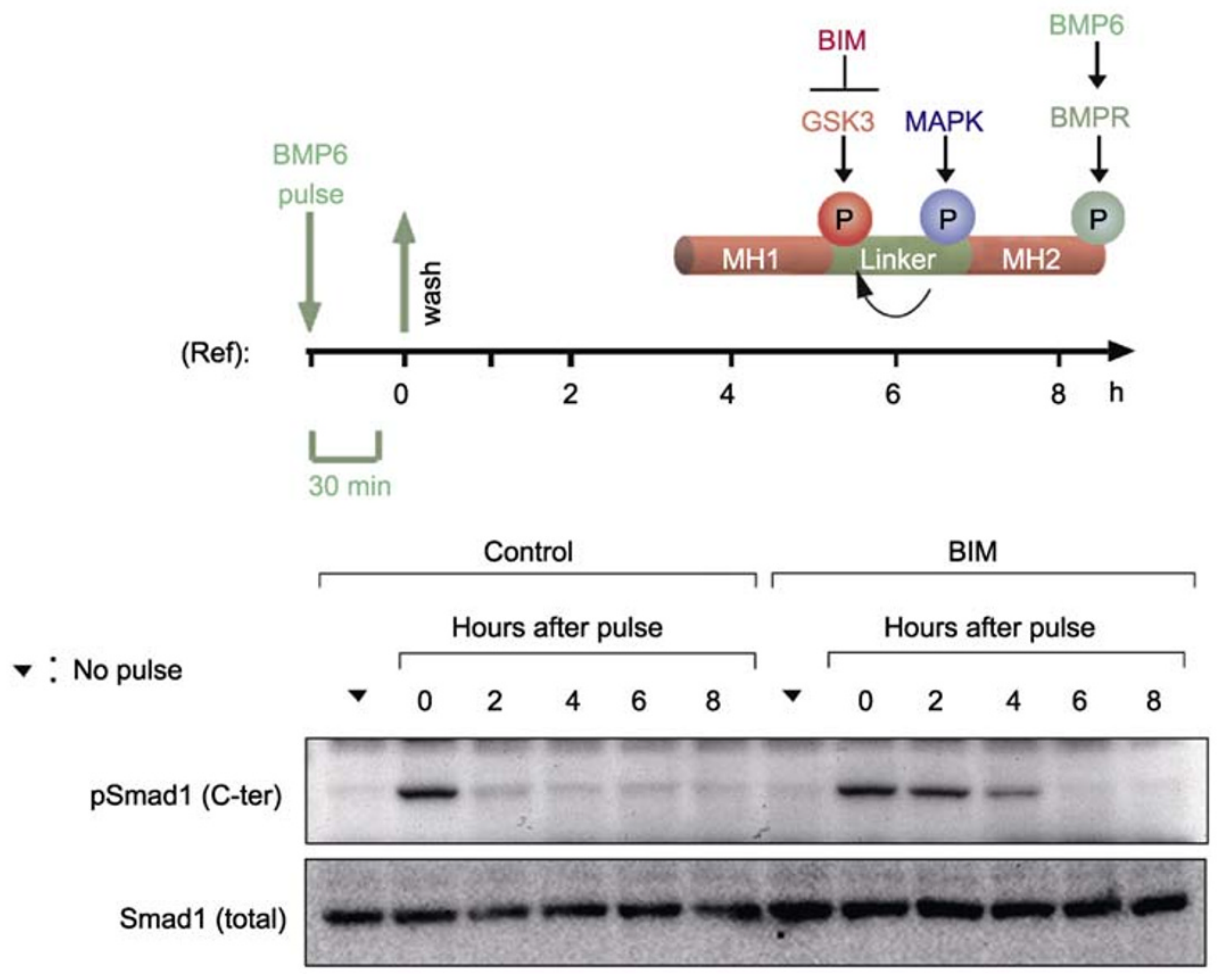

Figure 5. Bisindoylmaleimide I (BIM) elevates BMP-induced signaling. (A) BIM treatment elevates BMP-induced BRE-Luc activity in KS483 cells. RLU, relative luciferase unit; Co. control DMSO treatment. (B) Upper panel: Diagram of the model that BIM effects and the way that BMP ligand was added to the cells and then washed away. Ref: refer to (Fuentealba et al., 2007). Lower panel: Immunoblotting analysis of pSmad1 and total Smad1 level in KS483 cells after BIM and BMP treatment as indicated in upper panel.

affects BMP/Smad1 signaling as well. Immunoblot analysis showed that after BMP6 stimulation (30 min treatment and then washed away as shown in Fig. 5B top panel), the duration of BMP receptor induced C-terminal phosphorylated Smad1 was stabilized by BIM, which is consistent with the fact that BIM could suppress GSK3 $\beta$ kinase activity.

\section{BIM enhances BMP-induced mesenchymal stem cell differentiation into osteoblast}

Requirement for bone therapy is to increase bone formation by stimulating stem cells to commit to the osteoblast lineage, expanding the osteoprogenitor cell pool and promoting its 
differentiation with a final goal of forming a mineralized bone tissue (Lian et al., 2006).

Multipotent mesenchymal stem cells are able to differentiate into osteoblasts, adipocytes, chondrocytes, and myoblasts. The differentiation of mesenchymal stem cells is regulated by interaction with specific extracellular mediators. Both Wnt/B-catenin and BMP pathways play pivotal roles in triggering the differentiation of mesenchymal stem cells to osteoblast (Takada et al., 2009; Vukicevic and Grgurevic, 2009). Therefore, we extended to examine osteoblast differentiation from human mesenchymal stem cells (hMSCs). As shown in Fig. 6A, transient BIM treatment cooperatively accelerated bone formation together with following BMP stimulation as visualized by mineralization detection (Fig. 6A). Collectively, through suppressing GSK3 $\beta$ kinase activity, BIM activates Wnt/ $\beta$ signaling and enhances BMP/Smad responses, therefore promoting osteogenesis (Fig. 6B).

\section{DISCUSSION}

Bone resorption is balanced by activated osteoclasts andbone forming osteoblasts. While targeted inhibition of osteoclasts with bisphosphonates has achieved success in preventing bone loss, searching factors to stimulate bone formation has been challenging (Rosen, 2003; Zhao and Su, 2011).

Osteogenic differentiation of mesenchymal stem cells toward osteoprogenitor and osteoblastic cells is tightly regulated by several growth and transcription factors at the molecular level, in which Wnt/ $\beta$-catenin and BMP signaling is essentially involved. Therefore, searching factors/compo-

A
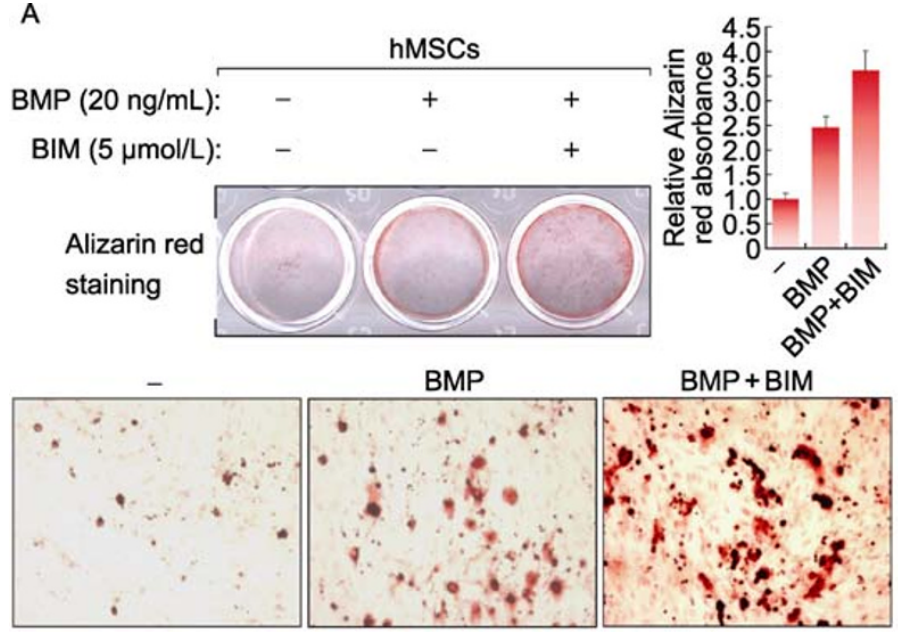

unds/drugs that can induce Wnt/ $\beta$-catenin and BMP signaling would be promising to identify potential candidates of promoting bone formation. GSK3 $\beta$ is a central component of $\beta$-catenin destruction complex. Blocking GSK3 $\beta$ kinase activity prevents the phosphorylation and ubiquitination-mediated degradation of $\beta$-catenin thus leading to the accumulation of cytosolic $\beta$-catenin and subsequent activation of Wnt signaling. The intensity of BMP signals was determined by BMP receptors via Smad1 C-terminal phosphorylations. GSK3 $\beta$ sequentially phosphorylates Smad1 linker region, causing polyubiquitinylation of C-terminal phosphorylated-Smad1. Therefore, antagonizing GSK3 $\beta$ kinase activity prevents not only $\beta$-catenin degradation but also the degradation of activated Smad1, leading to the prolonged duration of BMP signals. Here in the present study, we screened up to 40 kinds of kinase inhibitors and identified BIM as an efficient inducer of Wnt/ $\beta$-catenin activation by suppressing GSK3 $\beta$ kinase activity. Thus this study supported previous reports (Hers et al., 1999; Cho et al., 2008) and confirmed BIM as an agonist for Wnt/ $\beta$-catenin cascades in osteogenic cells. We further proved its role of extending BMP signaling and explored its application as an osteogenic inducer through multiple assays. ALP activity is an early marker for bone formation; we further confirmed read out of signaling and ALP assay by analyzing calcium deposition and the formation of mineralized matrix, occurring late in differentiation.

Another aspect that deserves discussion is the role of BIM as an inhibitor for protein kinase C (Pajak et al., 2008), a multifunctional protein kinase family whose members exhibit distinct properties (Dempsey et al., 2000). It was therefore of considerable interest to identify whether the observed effects

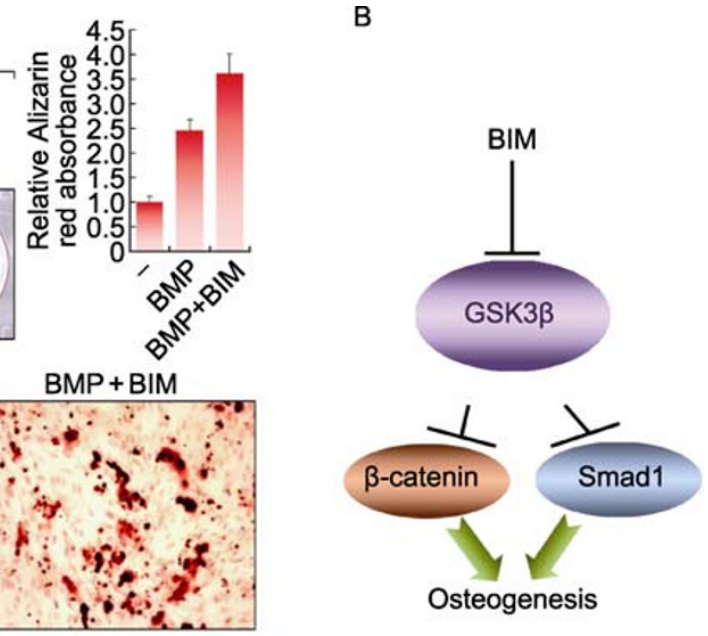

Figure 6. Bisindoylmaleimide I (BIM) enhances BMP-induced mesenchymal stem cell differentiation into osteoblast. (A) Upper left panel: hMSC cells were transiently treated with BIM for $1 \mathrm{~h}$ as indicated. The medium was then replaced by normal medium containing 10\% FBS, Vitamin C $(50 \mu \mathrm{g} / \mathrm{mL})$ and $\beta$-glycerolphosphate $(5 \mu \mathrm{mol} / \mathrm{L})$ with or without BMP ligand for another 12 days. Cells were then harvested for Alizarin Red staining. Upper right panel: Relative Alizarin Red absorbance analysis of upper left samples. Lower panel: Amplified view of upper left panel. (B) Working model of which BIM induces osteogenesis through suppressing GSK3 $\beta$ activity, subsequently strengthening $\beta$-catenin- and Smad1-mediated signaling. 
are related to consequences of PKC family or their individual isozyme's action. Of note, we observed a growth arrest effect in hMSCs by even suboptimal doses of BIM when it was long-time treated to cells, which was not considerably detected in preosteoblast. Whether this effect is due to suppression of PKC family members requires further investigations.

The fact that BIM enhances osteogenic differentiation emphasizes its physiological relevance of regulating Wnt/ $\beta$-catenin and BMP signals as a GSK3 $\beta$ inhibitor. Although much more work is needed to elucidate the possible application of BIM in bone disease, the present study provides a potential therapeutic method.

\section{MATERIALS AND METHODS}

\section{Reagents and plasmids}

$\beta$-catenin antibody sample kit (\#2951), GSK3 $\beta$ (\#9315) and phospho-GSK-3â (Ser9) (\#9336) antibodies were purchased from Cell Signaling Technology, Inc., USA. Actin (ab8227) was purchased from Abcam. Control and $\beta$-catenin siRNA were purchased from Thermo (Dharmacon RNAi Technologies), TopFlash-luciferase, FopFlashluciferase, LEF-luciferase, $\beta$-catenin SA mutant, Wnt3a, GSK3 $\beta$ wt, S9A, K85M and dnLEF-1 constructs were as described previously (Zhang et al., 2006; Zhou et al., 2008a, 2008b, 2011a).

\section{Cell culture}

C2C12, KS483, L cells and HEK293T cells were cultured in Dulbecco's modified Eagle's medium supplemented with $10 \%$ fetal bovine serum (Hyclone), nonessential amino acids, L-glutamine, and penicillin/streptomycin in a $5 \% \mathrm{CO}_{2}$-containing atmosphere at $37^{\circ} \mathrm{C}$.

\section{Luciferase reporter assay}

Cells were transfected and lysed as described (Zhang et al., 2006) and luciferase activities were measured by a luminometer (Berthold Technologies). Reporter activity was normalized to $\beta$-Gal activity, resulting from a cotransfected internal control plasmid. Experiments were performed in triplicate.

\section{Transfection and immunoblotting}

As previously described (Nie et al., 2010; Zhang et al., 2011; Zhou et al., 2011a, 2011b), cells were transiently transfected using Lipofectamine (Invitrogen). $40 \mathrm{~h}$ post-transfection, cells were lysed and immunoblotting was performed with specific antibody and secondary anti-mouse or anti-rabbit antibodies that were conjugated to horseradish peroxidase (Amersham Biosciences). Proteins were visualized by chemiluminescence.

\section{ALP staining and mineralization assays}

Histochemical examination of ALP activity in cells was performed using naphtol AS-MX phosphate (Sigma) and fast blue RR salt (Sigma) (van Dinther et al., 2010). For mineralization assay cells were washed with PBS, fixed with $3.7 \%$ formaldehyde, again washed with PBS and then incubated with $2 \%$ alizarin red $\mathrm{S}$ solution $(\mathrm{pH} 4.2)$ for $2 \mathrm{~min}$ and washed with distilled water (van Dinther et al., 2010).

\section{QRT-PCR (quantitative real-time-PCR)}

Total RNA was isolated using NucleoSpin ${ }^{\circledR}$ RNA II kit (BIOKÉ, Netherlands) reagent. $1 \mu \mathrm{g}$ RNA was reverse-transcribed using the RevertAid $^{\mathrm{TM}}$ First Strand cDNA Synthesis Kits (Fermentas). Quantitative real-time-PCR was accomplished with SYBR Green incorporation (Applied Bioscience) using a StepOne Plus real-time PCR system (Applied Bioscience). Results were normalized to those obtained with GAPDH. Primers used for QRT-PCR were: mGAPDH forward, 5'-AACTTTGGCATTGTGGAAGG-3'; mGAPDH reverse, 5'-ACACATTGGGGGTAGGAACA-3'; mRunx2 forward, 5'-GAATGCTTCATTCGCCTCAC-3'; mRunx2 reverse, 5'-GTGACCTGCAGAGATTAACC-3'; mOpg (osteoprotegerin) forward, 5'-CGCAAAAGTGTGGAATAGATGTCA-3'; mOpg (osteoprotegerin) reverse, 5'-GGTAGGAACAGCAAACCTGAAGA-3'.

\section{Preparation of cytosolic fractions}

Cytosolic and membrane fractions were prepared using the ProteoExtract kit (Calbiochem) according to the manufacturers' standard procedures.

\section{Statistical analysis}

Statistical analyses were performed with a two-tailed unpaired $t$ test. $P<0.05$ was considered statistically significant.

\section{ACKNOWLEDGEMENTS}

We are grateful to Dr. C. Löwik for KS483 cells, and Dr. Xi He of Harvard Medical School for constructs. This work was supported by the Netherlands Organization for Scientific Research (NWO 918.66.066), Netherlands Initiative for Regenerative Medicine and Centre for Biomedical Genetics; and National Natural Science Foundation of China (Grant Nos. 30900748 and 31171388) to H. H.

\section{ABBREVIATIONS}

ALP, alkaline phosphatase; BIM, bisindoylmaleimide I; BMPs, bone morphogenetic proteins; GSK3 $\beta$, glycogen synthase kinase $3 \beta$; hMSCs, human mesenchymal stem cells; TGF- $\beta$, transforming growth factor $\beta$

\section{REFERENCES}

Behrens, J., von Kries, J.P., Kühl, M., Bruhn, L., Wedlich, D., Grosschedl, R., and Birchmeier, W. (1996). Functional interaction of beta-catenin with the transcription factor LEF-1. Nature 382 , 638-642.

Boyden, L.M., Mao, J., Belsky, J., Mitzner, L., Farhi, A., Mitnick, M.A., Wu, D., Insogna, K., and Lifton, R.P. (2002). High bone density 
due to a mutation in LDL-receptor-related protein 5. N Engl J Med 346, 1513-1521.

Brunner, E., Peter, O., Schweizer, L., and Basler, K. (1997). pangolin encodes a Lef- 1 homologue that acts downstream of Armadillo to transduce the Wingless signal in Drosophila. Nature 385, 829-833.

Cho, M., Park, S., Gwak, J., Kim, D.E., Yea, S.S., Shin, J.G., and Oh, S. (2008). Bisindoylmaleimide I suppresses adipocyte differentiation through stabilization of intracellular beta-catenin protein. Biochem Biophys Res Commun 367, 195-200.

Dempsey, E.C., Newton, A.C., Mochly-Rosen, D., Fields, A.P., Reyland, M.E., Insel, P.A., and Messing, R.O. (2000). Protein kinase $\mathrm{C}$ isozymes and the regulation of diverse cell responses. Am J Physiol Lung Cell Mol Physiol 279, L429-L438.

Fang, D.X., Hawke, D., Zheng, Y.H., Xia, Y., Meisenhelder, J., Nika, H., Mills, G.B., Kobayashi, R., Hunter, T., and Lu, Z.M. (2007). Phosphorylation of beta-catenin by AKT promotes beta-catenin transcriptional activity. J Biol Chem 282, 11221-11229.

Fuentealba, L.C., Eivers, E., Ikeda, A., Hurtado, C., Kuroda, H., Pera, E.M., and De Robertis, E.M. (2007). Integrating patterning signals: Wnt/GSK3 regulates the duration of the BMP/Smad1 signal. Cell 131, 980-993.

Fujita, K., and Janz, S. (2007). Attenuation of WNT signaling by DKK-1 and -2 regulates BMP2-induced osteoblast differentiation and expression of OPG, RANKL and M-CSF. Mol Cancer 6, 71.

Gaur, T., Lengner, C.J., Hovhannisyan, H., Bhat, R.A., Bodine, P.V., Komm, B.S., Javed, A., van Wijnen, A.J., Stein, J.L., Stein, G.S., et al. (2005). Canonical WNT signaling promotes osteogenesis by directly stimulating Runx2 gene expression. J Biol Chem 280, 33132-33140.

Glass, D.A. 2nd, Bialek, P., Ahn, J.D., Starbuck, M., Patel, M.S., Clevers, H., Taketo, M.M., Long, F., McMahon, A.P., Lang, R.A., et al. (2005). Canonical Wnt signaling in differentiated osteoblasts controls osteoclast differentiation. Dev Cell 8, 751-764.

Gong, Y., Slee, R.B., Fukai, N., Rawadi, G., Roman-Roman, S., Reginato, A.M., Wang, H., Cundy, T., Glorieux, F.H., Lev, D., et al., and the Osteoporosis-Pseudoglioma Syndrome Collaborative Group. (2001). LDL receptor-related protein 5 (LRP5) affects bone accrual and eye development. Cell 107, 513-523.

He, X.C., Yin, T., Grindley, J.C., Tian, Q., Sato, T., Tao, W.A., Dirisina, R., Porter-Westpfahl, K.S., Hembree, M., Johnson, T., et al. (2007). PTEN-deficient intestinal stem cells initiate intestinal polyposis. Nat Genet 39, 189-198.

Hers, I., Tavaré, J.M., and Denton, R.M. (1999). The protein kinase C inhibitors bisindolylmaleimide I (GF 109203x) and IX (Ro 31-8220) are potent inhibitors of glycogen synthase kinase-3 activity. FEBS Lett 460, 433-436.

Hino, S., Tanji, C., Nakayama, K.I., and Kikuchi, A. (2005). Phosphorylation of beta-catenin by cyclic AMP-dependent protein kinase stabilizes beta-catenin through inhibition of its ubiquitination. Mol Cell Biol 25, 9063-9072.

Holmen, S.L., Zylstra, C.R., Mukherjee, A., Sigler, R.E., Faugere, M.C., Bouxsein, M.L., Deng, L., Clemens, T.L., and Williams, B.O. (2005). Essential role of beta-catenin in postnatal bone acquisition.
J Biol Chem 280, 21162-21168.

Honda, T., Yamamoto, H., Ishii, A., and Inui, M. (2010). PDZRN3 negatively regulates BMP-2-induced osteoblast differentiation through inhibition of Wnt signaling. Mol Biol Cell 21, 3269-3277.

Hsu, S.C., Galceran, J., and Grosschedl, R. (1998). Modulation of transcriptional regulation by LEF-1 in response to Wnt-1 signaling and association with beta-catenin. Mol Cell Biol 18, 4807-4818.

Korchynskyi, O., and ten Dijke, P. (2002). Identification and functional characterization of distinct critically important bone morphogenetic protein-specific response elements in the Id1 promoter. J Biol Chem 277, 4883-4891.

Korinek, V., Barker, N., Morin, P.J., vanWichen, D., deWeger, R., Kinzler, K.W., Vogelstein, B., and Clevers, H. (1997). Constitutive transcriptional activation by a beta-catenin-Tcf complex in APC(-/-) colon carcinoma. Science 275, 1784-1787.

Kramer, I., Halleux, C., Keller, H., Pegurri, M., Gooi, J.H., Weber, P.B., Feng, J.Q., Bonewald, L.F., and Kneissel, M. (2010). Osteocyte $\mathrm{Wnt} /$ beta-catenin signaling is required for normal bone homeostasis. Mol Cell Biol 30, 3071-3085.

Lian, J.B., Stein, G.S., Javed, A., van Wijnen, A.J., Stein, J.L., Montecino, M., Hassan, M.Q., Gaur, T., Lengner, C.J., and Young, D.W. (2006). Networks and hubs for the transcriptional control of osteoblastogenesis. Rev Endocr Metab Disord 7, 1-16.

Little, R.D., Carulli, J.P., Del Mastro, R.G., Dupuis, J., Osborne, M., Folz, C., Manning, S.P., Swain, P.M., Zhao, S.C., Eustace, B., et al. (2002). A mutation in the LDL receptor-related protein 5 gene results in the autosomal dominant high-bone-mass trait. Am J Hum Genet 70, 11-19.

Nie, J., Wang, H., He, F., and Huang, H. (2010). Nusap1 is essential for neural crest cell migration in zebrafish. Protein Cell 1, 259-266.

Pajak, B., Orzechowska, S., Gajkowska, B., and Orzechowski, A. (2008). Bisindolylmaleimides in anti-cancer therapy - more than PKC inhibitors. Adv Med Sci 53, 21-31.

Qiang, Y.W., Barlogie, B., Rudikoff, S., and Shaughnessy, J.D. Jr. (2008). Dkk1-induced inhibition of Wnt signaling in osteoblast differentiation is an underlying mechanism of bone loss in multiple myeloma. Bone 42, 669-680.

Rawadi, G., Vayssière, B., Dunn, F., Baron, R., and Roman-Roman, S. (2003). BMP-2 controls alkaline phosphatase expression and osteoblast mineralization by a Wnt autocrine loop. J Bone Miner Res 18, 1842-1853.

Rosen, C.J. (2003). The cellular and clinical parameters of anabolic therapy for osteoporosis. Crit Rev Eukaryot Gene Expr 13, 25-38.

Spencer, G.J., Utting, J.C., Etheridge, S.L., Arnett, T.R., and Genever, P.G. (2006). Wnt signalling in osteoblasts regulates expression of the receptor activator of NFkappaB ligand and inhibits osteoclastogenesis in vitro. J Cell Sci 119, 1283-1296.

Takada, I., Kouzmenko, A.P., and Kato, S. (2009). Wnt and PPARgamma signaling in osteoblastogenesis and adipogenesis. Nat Rev Rheumatol 5, 442-447.

Tang, N., Song, W.X., Luo, J., Luo, X., Chen, J., Sharff, K.A., Bi, Y., He, B.C., Huang, J.Y., Zhu, G.H., et al. (2009). BMP-9-induced osteogenic differentiation of mesenchymal progenitors requires 
functional canonical Wnt/beta-catenin signalling. J Cell Mol Med 13, 2448-2464.

Taurin, S., Sandbo, N., Qin, Y.M., Browning, D., and Dulin, N.O. (2006). Phosphorylation of beta-catenin by cyclic AMP-dependent protein kinase. J Biol Chem 281, 9971-9976.

ten Dijke, P. (2006). Bone morphogenetic protein signal transduction in bone. Curr Med Res Opin 22, S7-S11.

van Dinther, M., Visser, N., de Gorter, D.J., Doorn, J., Goumans, M.J., de Boer, J., and ten Dijke, P. (2010). ALK2 R206H mutation linked to fibrodysplasia ossificans progressiva confers constitutive activity to the BMP type I receptor and sensitizes mesenchymal cells to BMP-induced osteoblast differentiation and bone formation. J Bone Miner Res 25, 1208-1215.

Vukicevic, S., and Grgurevic, L. (2009). BMP-6 and mesenchymal stem cell differentiation. Cytokine Growth Factor Rev 20, 441-448.

Zhang, B., and Ma, J.X. (2010). Wht pathway antagonists and angiogenesis. Protein Cell 1, 898-906.

Zhang, L., Gao, X., Wen, J., Ning, Y., and Chen, Y.G. (2006). Dapper 1 antagonizes Wnt signaling by promoting dishevelled degrada- tion. J Biol Chem 281, 8607-8612.

Zhang, L., Zhou, F., van Laar, T., Zhang, J., van Dam, H., and Ten Dijke, P. (2011). Fas-associated factor 1 antagonizes Wnt signaling by promoting beta-catenin degradation. Mol Biol Cell 22, 1617-1624.

Zhao, A.Z., and Su, D. (2011). An "endocrine function of" bone to pick: starting with males. Protein Cell 2, 171-172.

Zhou, F., van Laar, T., Huang, H., and Zhang, L. (2011a). APP and APLP1 are degraded through autophagy in response to proteasome inhibition in neuronal cells. Protein Cell 2, 377-383.

Zhou, F., Zhang, L., Gong, K., Lu, G., Sheng, B., Wang, A., Zhao, N., Zhang, X., and Gong, Y. (2008a). LEF-1 activates the transcription of E2F1. Biochem Biophys Res Commun 365, 149-153.

Zhou, F., Zhang, L., van Laar, T., van Dam, H., and Ten Dijke, P. (2011b). GSK3 beta inactivation induces apoptosis of leukemia cells by repressing the function of c-Myb. Mol Biol Cell 22, 3533-3540.

Zhou, F., Zhang, L., Wang, A., Song, B., Gong, K., Zhang, L., Hu, M., Zhang, X., Zhao, N., and Gong, Y. (2008b). The association of GSK3 beta with E2F1 facilitates nerve growth factor-induced neural cell differentiation. J Biol Chem 283, 14506-14515. 